\title{
MODELO DE RESPUESTA A LA ACREDITACIÓN INSTITUCIONAL. LA EXPERIENCIA DE LA UNIVERSIDAD DE LOS LAGOS
}

\section{Introducción}

La Universidad de Los Lagos (ULagos) es una institución estatal creada en 1993, pero cuyos orígenes se remontan a alrededor de treinta años antes, periodo en que tuvo diferentes denominaciones, como parte de la Universidad de Chile y de la ex Universidad Técnica del Estado, y luego, a partir de 1981, como institución autónoma: el Instituto Profesional de Osorno. El año 2005 resolvió presentarse voluntariamente al proceso de acreditación institucional que desarrollaba en carácter experimental la Comisión Nacional de Acreditación de Pregrado (CNAP) (CNAP, 2007). El dictamen No 68 de enero de 2006 de la CNAP determinó su no acreditación institucional debido, principalmente, al desarrollo de sedes, a lo largo de todo el país, en las cuales se impartían programas "especiales" de carreras conducentes a títulos profesionales y técnicos, sin ingresos a través de pruebas nacionales. Se cuestionó la calidad de dichos programas y la existencia de notables diferencias en la gestión y condiciones de operación respecto de los programas tradicionales que se impartían en las sedes centrales, los cuales tenían mecanismos de admisión mediante pruebas nacionales. El desarrollo explosivo de estos programas "especiales" de pregrado, como causal principal de la no acreditación institucional, debe ser entendido como resultado de la contradicción entre lograr la sostenibilidad corporativa a través del autofinanciamiento y las limitaciones a la autonomía que imponen procesos regulatorios basados en la calidad que deben tener los servicios educativos (Garrido y López, 2007).

Como consecuencia de las diversas medidas adoptadas para superar esta situación, que impactó no sólo en la imagen institucional sino también en su economía, la ULagos logró en un nuevo proceso la acreditación institucional por un periodo de tres años (Acuerdo 
de acreditación institucional $\mathrm{N}^{\circ}$ 2, de noviembre de 2007, de la Comisión Nacional de Acreditación, CNA). Este nuevo proceso está institucionalizado por la ley $\mathrm{N}^{\circ} 20.129$, que establece un sistema formal de aseguramiento de la calidad de la educación superior chilena.

Este caso reviste interés, por cuanto evidencia los resultados de la aplicación de un modelo de respuesta a los procesos de acreditación institucional, lo que ha comprometido cambios políticos, estratégicos y operacionales.

\section{Componentes del modelo de respuesta a la no acreditación institucional}

Después del análisis de la situación planteada por el dictamen negativo de la CNAP, el equipo directivo superior de la ULagos elaboró un modelo formal, integrador de diversas medidas conducentes al diseño de un Plan de Mejoramiento Institucional, que permitiera superar la situación y orientar el desarrollo futuro de la universidad. Las medidas correctivas fueron contingentes, estratégicas, de soporte y asociadas al proceso de autoevaluación, todas ellas interrelacionadas sistémicamente y formalizadas en planes, cambios organizacionales, procesos de análisis y socialización de los avances (figura 1). 
148 MODELO DE RESPUESTA A LA ACREDITACIÓN INSTITUCIONAL - Andrea R. Minte, Daniel A. López

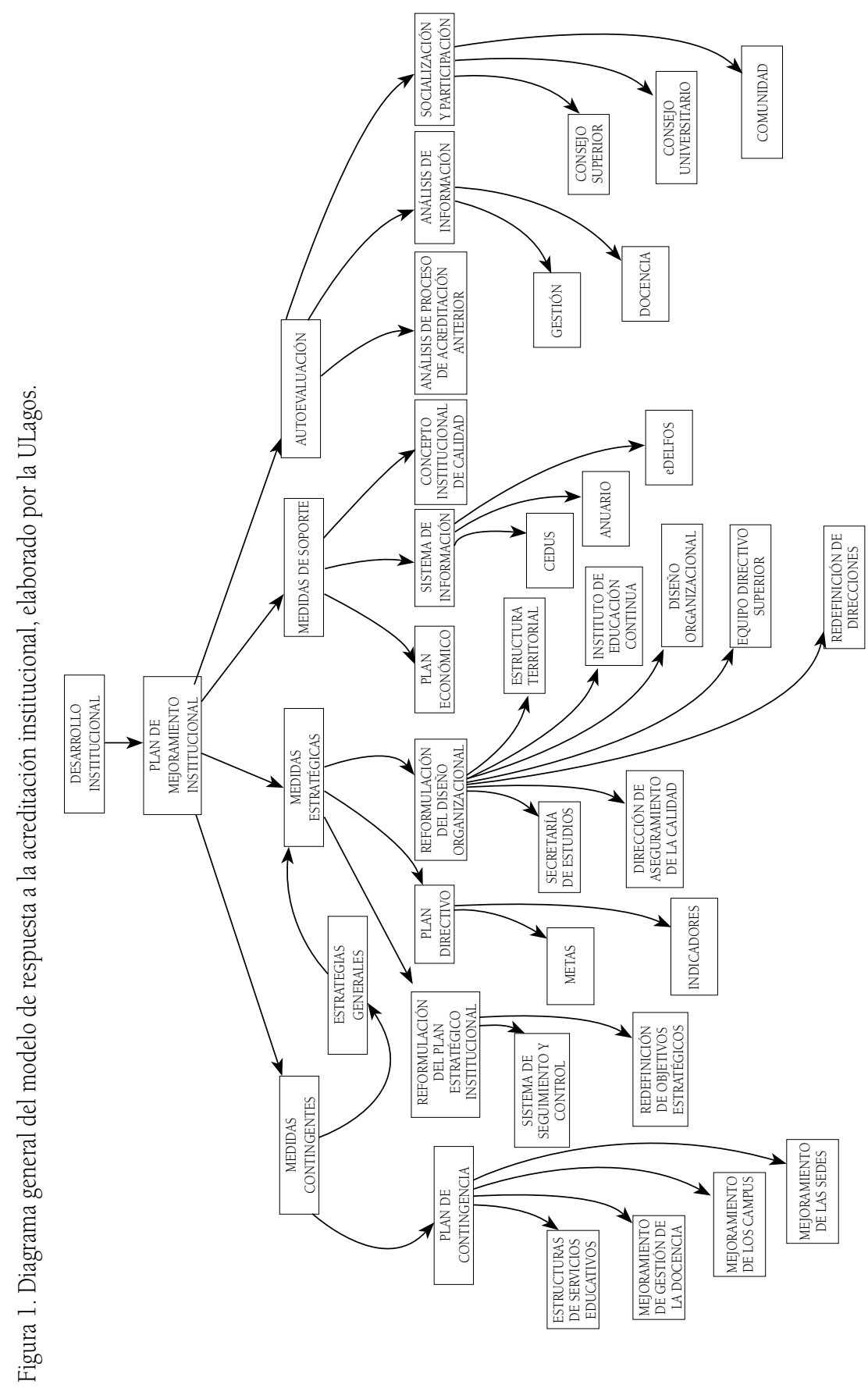


El componente central del funcionamiento estratégico de la universidad consistió en la formalización de un modelo unificador e interactivo, lo cual también requiere definir objetivos de mediano y largo plazo, programar y segmentar actividades, establecer ventajas comparativas, medir resultados e impactos y basar las decisiones de la gestión en información pertinente y confiable (Hax y Majluf, 1996).

\section{Medidas contingentes}

Se elaboró un Plan de Contingencia para la acreditación institucional y de carreras que consideró cuatro ámbitos de cambio: estructura de los servicios educativos, mejoramiento de la gestión de la docencia, de los servicios educativos en los campus y de los servicios educativos en las sedes. Este último aspecto implicó establecer diferencias funcionales en la cobertura de las actividades docentes desarrolladas en los enclaves territoriales con que contaba la universidad.

El Plan de Contingencia consideró un conjunto de 40 medidas con 60 metas y sus respectivos indicadores de resultados, destinados a enfrentar las situaciones más urgentes y establecer los límites y lineamentos para las medidas de corto plazo.

La estructura de los servicios se relaciona con que la ULagos definió dos tipos de programas según el tipo de ingreso: programas de pregrado profesionales y técnicos con ingreso vía Prueba de Selección Universitaria (PSU), y programas con otros tipos de ingresos, en los cuales se privilegia la experiencia laboral del alumno. La estructura territorial de la universidad no estaba debidamente formalizada, a pesar de las deficiencias en coberturas y servicios. Por ello se establecieron diferencias entre campus y sedes. En los campus es posible realizar todo tipo de actividades académicas (en Osorno, Puerto Montt y Santiago), en tanto que en las sedes sólo se pueden impartir carreras profesionales y técnicas no consideradas estrictamente como universitarias en la Ley Orgánica Constitucional de Enseñanza (LOCE), y con ingresos alternativos a la PSU. Sólo siguieron con ingreso de estudiantes 14 sedes, lo que corresponde a casi un tercio de las existentes. La decisión anterior significó la segmentación de actividades, de modo de facilitar cambios en la estructura corporativa. 
150 MODELO DE RESPUESTA A LA ACREDITACIÓN INSTITUCIONAL - Andrea R. Minte, Daniel A. López

En el mejoramiento de gestión de docencia, las principales medidas fueron la creación de la Dirección de Aseguramiento de la Calidad, dependiente de la nueva Vicerrectoría de Planificación y Desarrollo, y cambios funcionales, tales como la instalación de la gestión estratégica en el nivel directivo y la implementación de sistemas de información para la toma de decisiones.

Para el mejoramiento de los servicios educativos en los campus se realizó un análisis exhaustivo, adoptándose medidas generales de mejoramiento de la calidad, entre otras: implementación y seguimiento de la reforma educativa que considera el enfoque curricular basado en competencias en todas las carreras; establecimiento de un sistema computacional de gestión; mejoramiento del servicio de apoyo a las actividades docentes, principalmente bibliotecas, salas de estudio y laboratorios; mejoramiento del sistema de evaluación docente y transformación de la Dirección de Docencia de Pregrado. Tradicionalmente, esta dirección cumplía sólo tareas administrativas, las que fueron transferidas a una Secretaría de Estudios, radicándose ahora en aquella la gestión curricular y los procesos de enseñanzaaprendizaje en función de un modelo educativo institucional definido durante el proceso de autoestudio.

Para el mejoramiento de las sedes se contrató una consultoría externa, de modo de verificar el real estado de estas unidades. Paralelamente, se estableció que en ellas sólo podían impartirse programas de pregrado sin ingreso mediante PSU sólo en tres áreas disciplinarias, definidas sobre la base de los recursos, capacidades instaladas y sus opciones de proyección. De este modo, se focalizaron los esfuerzos para el mejoramiento de la calidad, estableciéndose además requisitos mínimos para el funcionamiento de las sedes, a través de indicadores provistos de valores mínimos respecto de infraestructura, equipamiento, recursos humanos y mecanismos de apoyo a los estudiantes. Además, se instauró un sistema de pruebas nacionales para evaluar los procesos de enseñanza-aprendizaje en las asignaturas dictadas en un mismo programa en todas las sedes; se mejoraron las bibliotecas y centros virtuales de documentación y se amplió la cobertura de textos de autoaprendizaje. Se capacitó a más de seiscientos docentes en enseñanza universitaria en forma 
presencial y virtual a través del país. Asimismo, se buscó mejorar e integrar la gestión académica, administrativa y financiera mediante la implementación de un sistema computacional institucional.

\section{Medidas estratégicas}

Se orientaron a tres aspectos: Plan Estratégico de Desarrollo Institucional, cambios organizacionales y elaboración de un Plan Directivo. El Plan Estratégico de Desarrollo vigente fue reformulado, ampliando su periodo de vigencia, con el fin de dar continuidad a las medidas adoptadas. El replanteamiento de los objetivos estratégicos y la implementación de un sistema de seguimiento y control fueron las mayores innovaciones. El instrumento para realizar estos cambios fue la introducción de la herramienta de gestión Balanced Scorecard, con la cual se diseñó un mapa y una matriz estratégica que permiten establecer relaciones entre objetivos y hacer el seguimiento del Plan en términos de cuatro perspectivas: de alumnos, financiera, de procesos internos, de aprendizaje y crecimiento (Olve et al., 2000).

El principal cambio fue la reformulación del diseño organizacional, desde el jerárquico o mecánico tradicional a uno orgánico, considerado más adecuado para los tiempos de crisis y de adaptación a los cambios. El diseño organizacional orgánico privilegia las vinculaciones horizontales y basa su funcionamiento en las comunicaciones mediante todo canal, otorgando menos importancia a la división del trabajo, a la unicidad en la toma de decisiones y a la rigidez estructural (Himmel y Maltes, 1992). Durante todo el periodo de elaboración del informe de autoevaluación institucional, el equipo directivo superior funcionó como una estructura orgánica, con jerarquías de autoridad descentralizadas, pocas reglas o procedimientos, distribución ambigua del trabajo y una coordinación de las actividades informal y personal.

La medida estratégica de separar los campus de las sedes ordenó la estructura interna, creándose paralelamente el Instituto de Educación Continua, entidad de carácter transicional cuyo objetivo principal es ocuparse del adecuado funcionamiento de las 14 sedes vigentes y de aquellas discontinuadas que aún poseen programas de formación en 
152 MODELO DE RESPUESTA A LA ACREDITACIÓN INSTITUCIONAL - Andrea R. Minte, Daniel A. López

proceso o en etapa de finalización, mientras los alumnos pertenezcan a la universidad. A partir de 2008 se creó un instituto profesional privado y autónomo, el cual irá absorbiendo paulatinamente los servicios docentes impartidos en las sedes, de modo que cuando se alcance el estado de régimen, la universidad sólo contará en su estructura territorial con tres campus y será propietaria de un instituto profesional privado con programas formativos a través del país.

Otros cambios organizacionales fueron la creación de dos vicerrectorías: Planificación y Desarrollo y Gestión Corporativa, esta última encargada de la dimensión territorial de la universidad. En la Vicerrectoría de Planificación y Desarrollo se integró la generación de información para la toma de decisiones, la planificación y control estratégico, así como el aseguramiento de la calidad. El Centro de Estudios Universitarios fue reorientado en sus objetivos, priorizando entre sus tareas la generación de un sistema de información para mejorar la toma de decisiones y la participación en la gestión, así como para realizar estudios y análisis institucionales. Entre otros aspectos, se han realizado estudios publicados sobre necesidades de información y uso de información en la gestión institucional; aportes de la didáctica a la comprensión en la docencia universitaria; calidad en la educación superior; uso y políticas de uso de los TIC en la universidad y educación superior para trabajadores. También se readecuó la Dirección de Planificación, otorgándosele un carácter eminentemente técnico. Su función primaria fue la instalación de la gestión estratégica de la universidad, incluyendo procesos de control. Para ello se implementó el alineamiento del Plan Estratégico de Desarrollo Institucional con los planes operativos de las direcciones centrales académicas y administrativas, incorporando softwares especializados que permitieran el seguimiento permanente de metas e indicadores. En la Dirección de Aseguramiento de la Calidad se radicaron los procesos de autoevaluación institucional y de carreras, el seguimiento de los acuerdos de autoevaluación y acreditación y de los planes de mejoramiento de cada carrera acreditada, entre otras funciones.

El Plan Directivo anual de las 18 direcciones centrales de la universidad consideró como exigencias, en concordancia con las definiciones estratégicas institucionales, contar con líneas de acción 
propias, metas, indicadores de resultados y tiempo de ejecución para cada una de las direcciones. Ello permitirá realizar procesos de evaluación y rendición de cuentas ("accountability"), que se espera también replicar en las direcciones de departamentos académicos con el fin de que estos procesos se puedan realizar en todos los estamentos de la universidad.

\section{Medidas de soporte}

Para enfrentar las limitaciones de información, se creó un portal sobre educación superior CEDUS (www.cedus.cl) con información actualizada tanto de la ULagos como de otras universidades nacionales y extranjeras. Hasta hoy registra más de 230.000 nuevos usuarios, con una frecuencia de visitas que fluctúa entre 2.000 a 4.000 por semana. El análisis de las visitas internas reveló que casi la mitad fueron sobre aspectos normativos. Las externas fueron principalmente acerca de temas de acreditación y calidad, redes universitarias y gestión. Asimismo, se inició la edición de un anuario institucional con descriptores e indicadores académicos que contiene información básica sobre la institución: síntesis histórica, visión, misión, estructura organizacional, Plan Estratégico de Desarrollo Institucional, programas de formación, recursos humanos -académicos y no académicos-, recursos físicos -infraestructura y equipamiento-, así como indicadores de investigación científica y tecnológica y extensión. También, indicadores financieros de los últimos tres años, con los cuales ha sido posible hacer procesos de "benchmarking" con otras universidades derivadas. Por último, se implementó una plataforma informática de última generación que ya opera en estado de régimen para la gestión administrativo-contable y en el corto plazo lo hará para la gestión académica. Asimismo, a través del software I Think, se elaboraron modelos dinámicos referentes a la gestión para establecer relaciones entre variables y enfrentar aspectos prospectivos.

\section{Medidas asociadas al proceso de autoevaluación}

En primer término, se estableció un concepto institucional de calidad con el fin de disponer de un referente común en todos los niveles institucionales. A partir de una propuesta técnica, los cuerpos 
154 MODELO DE RESPUESTA A LA ACREDITACIÓN INSTITUCIONAL - Andrea R. Minte, Daniel A. López

colegiados superiores -Consejo Superior y Consejo Académicollegaron a acuerdos sobre el tema.

El proceso de autoevaluación institucional se realizó sobre la base de un análisis riguroso de la documentación del proceso anterior, considerando principalmente las debilidades detectadas por el Informe del Comité de Pares y el dictamen de la CNAP. Junto con recolectar la información dispersa en diferentes direcciones y jefaturas, se realizó en paralelo la aplicación de encuestas (3.300) a funcionarios, académicos y estudiantes de los tres campus y de todas las sedes (vigentes y discontinuadas). Además, se realizaron entrevistas en profundidad a autoridades universitarias relativas el tema de gestión.

La elaboración del Informe de Autoevaluación institucional estuvo a cargo de un grupo de personas designadas por el rector y fue liderado por el vicerrector de Planificación y Desarrollo, quien contó con la colaboración de un equipo técnico ad hoc y con la participación de muchas personas que proveyeron información específica en más de 100 informes internos formales. Un censo no exhaustivo de los cambios realizados se muestra en la tabla 1 .

Tabla 1. Síntesis de los cambios efectuados en la ULagos, producto de los sucesivos procesos de acreditación institucional.

\begin{tabular}{|l|l|l|}
\hline $\begin{array}{l}\text { Situación en el } \\
\text { momento del } \\
\text { primer proceso de } \\
\text { autoevaluación. }\end{array}$ & Situación posterior. & Cambios realizados. \\
\hline $\begin{array}{l}\text { Falta de una } \\
\text { estructura } \\
\text { territorial formal. }\end{array}$ & $\begin{array}{l}\text { Definición de tres campus: Osorno, } \\
\text { Puerto Montt y Santiago y 14 Sedes } \\
\text { en el país. } \\
\text { Se inició estudio para crear un centro } \\
\text { de formación técnica (CFT) para } \\
\text { carreras técnicas. } \\
\text { Se instaló un instituto profesional } \\
\text { (IP) autónomo y privado, para } \\
\text { la matrícula 2008 en adelante de } \\
\text { programas especiales que se dicten } \\
\text { adquisición de un instituto } \\
\text { profesional autónomo. } \\
\text { Se crea el Instituto de Educación } \\
\text { Continua, del cual dependen } \\
\text { temporalmente las sedes en tanto el } \\
\text { instituto profesional no alcance el } \\
\text { estado de régimen, absorbiendo la } \\
\text { totalidad de las sedes. }\end{array}$ \\
\hline
\end{tabular}




\begin{tabular}{|c|c|c|}
\hline $\begin{array}{l}\text { Limitaciones en } \\
\text { los sistemas de } \\
\text { planificación y } \\
\text { control estratégico }\end{array}$ & $\begin{array}{l}\text { Plan Estratégico de Desarrollo } \\
\text { Institucional reformulado, } \\
\text { extendiéndose el periodo de su } \\
\text { vigencia; se incorporaron aspectos } \\
\text { técnicos de control estratégico. } \\
\text { Existe un Plan Directivo formal para } \\
\text { todas las direcciones centrales. }\end{array}$ & $\begin{array}{l}\text { Se ha efectuado un seguimiento } \\
\text { del Plan Estratégico de Desarrollo } \\
\text { Institucional, verificándose su } \\
\text { avance; se han realizado ajustes a las } \\
\text { actuales condiciones reformulándose } \\
\text { en base a las perspectivas del } \\
\text { Balanced Scorecard. } \\
\text { Se formuló un Plan Directivo que } \\
\text { establece un sistema planificado } \\
\text { de control y retroalimentación } \\
\text { para las tareas operativas de las } \\
\text { direcciones centrales, académicas y } \\
\text { administrativas. } \\
\text { Sistema de control estratégico y } \\
\text { operacional. }\end{array}$ \\
\hline $\begin{array}{l}\text { (*)Las unidades } \\
\text { que generan } \\
\text { información } \\
\text { no cuentan } \\
\text { con adecuada } \\
\text { coordinación e } \\
\text { integración. No } \\
\text { existe una unidad } \\
\text { que provea de } \\
\text { indicadores } \\
\text { integrados para la } \\
\text { gestión. }\end{array}$ & $\begin{array}{l}\text { Base documental en educación } \\
\text { superior, CEDUS.CL, implementada, } \\
\text { la que provee información } \\
\text { institucional y sobre la educación } \\
\text { superior. } \\
\text { Existe un anuario institucional } \\
\text { con descriptores e indicadores de } \\
\text { gestión. } \\
\text { La Dirección de Planificación ha } \\
\text { integrado indicadores en gestión; } \\
\text { La Dirección de Aseguramiento } \\
\text { de la Calidad lo hace a través de } \\
\text { indicadores académicos. } \\
\text { El sistema informático eDelfos, de } \\
\text { última generación, opera en estado } \\
\text { de régimen en gestión administrativa } \\
\text { y se realiza su implementación en } \\
\text { gestión académica. } \\
\text { Se cuenta con informes de } \\
\text { consultorías externas de alto nivel } \\
\text { en los siguientes temas: aspectos } \\
\text { organizacionales; funcionamiento } \\
\text { de sedes; carreras pedagógicas; } \\
\text { evaluación de recursos humanos; } \\
\text { diseños curriculares; control de } \\
\text { gestión, entre otros aspectos. }\end{array}$ & $\begin{array}{l}\text { Se creó un dominio para el portal } \\
\text { CEDUS.CL. Se ha digitalizado y } \\
\text { clasificado la información con la } \\
\text { que se está poblando. Su diseño y } \\
\text { estructura fueron definidos. } \\
\text { Se generó un anuario institucional, } \\
\text { que estuviese en concordancia con el } \\
\text { proyecto de Sistema de Información } \\
\text { de la Educación Superior (SIES). } \\
\text { Se reforzó técnicamente la Dirección } \\
\text { de Planificación, cambiando } \\
\text { su dependencia jerárquica a la } \\
\text { vicerrectoría de Planificación y } \\
\text { Desarrollo, la cual también incluye } \\
\text { la Dirección de Aseguramiento de } \\
\text { la Calidad y el Centro de Estudios } \\
\text { Universitarios. } \\
\text { Se adquirió el sistema de gestión } \\
\text { informática eDelfos, a un costo } \\
\text { total a la fecha que supera U\$1,5 } \\
\text { millones, que incluye servicios de } \\
\text { información. } \\
\text { Se estableció una cartera de } \\
\text { consultorías en temas críticos. }\end{array}$ \\
\hline
\end{tabular}


156 MODELO DE RESPUESTA A LA ACREDITACIÓN INSTITUCIONAL - Andrea R. Minte, Daniel A. López

\begin{tabular}{|c|c|c|}
\hline $\begin{array}{l}\text { Limitaciones } \\
\text { en definiciones } \\
\text { estratégicas. }\end{array}$ & $\begin{array}{l}\text { Se cuenta con dos nuevas } \\
\text { vicerrectorías: de Planificación y } \\
\text { Desarrollo y de Gestión Corporativa, } \\
\text { encargadas de las estrategias } \\
\text { relacionadas a planificación/ } \\
\text { información/ calidad y del desarrollo } \\
\text { territorial, respectivamente. } \\
\text { Funcionamiento del Comité } \\
\text { Directivo Superior integrado por } \\
\text { el rector, vicerrectores y secretario } \\
\text { general, que posibilita el análisis } \\
\text { y la toma de decisiones en el nivel } \\
\text { estratégico. }\end{array}$ & $\begin{array}{l}\text { Se crearon formalmente dos nuevas } \\
\text { vicerrectorías de carácter técnico, } \\
\text { para reforzar el trabajo en el nivel } \\
\text { estratégico; ambas están dotadas de } \\
\text { equipos técnicos. } \\
\text { El Comité Directivo Superior } \\
\text { opera semanalmente, elaborándose } \\
\text { informes técnicos destinados a la } \\
\text { toma de decisiones. Además se } \\
\text { generó el Plan de Contingencia para } \\
\text { la acreditación institucional y de } \\
\text { carreras. } \\
\text { Se reformuló el Plan Estratégico de } \\
\text { Desarrollo Institucional. } \\
\text { Se diseñó un Plan Directivo. } \\
\text { Se conduce el proceso de } \\
\text { autoevaluación, en el nivel } \\
\text { estratégico. }\end{array}$ \\
\hline $\begin{array}{l}\text { Limitaciones en } \\
\text { la organización } \\
\text { institucional } \\
\text { para lograr el } \\
\text { aseguramiento de } \\
\text { la calidad de las } \\
\text { sedes. }\end{array}$ & $\begin{array}{l}\text { Está en funcionamiento la Dirección } \\
\text { de Aseguramiento de la Calidad. } \\
\text { El nivel estratégico opera con un } \\
\text { diseño organizacional orgánico. }\end{array}$ & $\begin{array}{l}\text { Se creó la Dirección de } \\
\text { Aseguramiento de la Calidad. } \\
\text { Se generó un cambio en el } \\
\text { nivel estratégico de un diseño } \\
\text { organizacional mecánico a otro } \\
\text { orgánico. }\end{array}$ \\
\hline $\begin{array}{l}\text { Falta una unidad } \\
\text { responsable de } \\
\text { los procesos de } \\
\text { aseguramiento de } \\
\text { la calidad. }\end{array}$ & $\begin{array}{l}\text { Esta tarea es asumida por la } \\
\text { Dirección de Aseguramiento de la } \\
\text { Calidad. }\end{array}$ & $\begin{array}{l}\text { Se creó la Dirección de } \\
\text { Aseguramiento de la Calidad. }\end{array}$ \\
\hline $\begin{array}{l}\text { Se carece de } \\
\text { un sistema } \\
\text { planificado para } \\
\text { el mejoramiento y } \\
\text { aseguramiento de } \\
\text { la calidad. }\end{array}$ & $\begin{array}{l}\text { Existe un Plan Contingente para } \\
\text { la acreditación institucional y de } \\
\text { carreras. }\end{array}$ & $\begin{array}{l}\text { El Plan Contingente fue elaborado } \\
\text { definiendo un plan de mejoramiento } \\
\text { Implica una inversión de alrededor } \\
\text { de } \$ 2.300 \text { millones en las áreas de: } \\
\text { estructura de servicios educativos, } \\
\text { mejoramiento de gestión de la } \\
\text { calidad, mejoramiento de campus y } \\
\text { mejoramiento de sedes. }\end{array}$ \\
\hline
\end{tabular}




\begin{tabular}{|c|c|c|}
\hline $\begin{array}{l}\text { Limitaciones en } \\
\text { la estructura y } \\
\text { funcionamiento } \\
\text { de la docencia } \\
\text { de pregrado, } \\
\text { particularmente en } \\
\text { las sedes Osorno y } \\
\text { Puerto Montt. }\end{array}$ & \begin{tabular}{|l|} 
La actual Dirección de Docencia \\
de pregrado tiene como funciones \\
la gestión docente, los procesos de \\
mejoramiento curricular de todas las \\
carreras de campus y sedes, aspectos \\
no considerados en la estructura \\
anterior. \\
Los aspectos administrativos se \\
centralizan en la Secretaría de \\
Estudios y en la Oficina de Títulos \\
y Grados. \\
La Dirección de Asuntos \\
Estudiantiles realiza un proceso de \\
aseguramiento de la calidad de su \\
gestión, que se inicia también en la \\
Dirección de Docencia de pregrado.
\end{tabular} & $\begin{array}{l}\text { Se redefinió funcionalmente la } \\
\text { Dirección de Docencia de Pregrado. } \\
\text { Se creó la Secretaría de Estudios. } \\
\text { Se reasignó la Oficina de Títulos y } \\
\text { Grados. } \\
\text { La Dirección de Asuntos } \\
\text { Estudiantiles, inicia la } \\
\text { implementación de normas ISO. }\end{array}$ \\
\hline \begin{tabular}{|l} 
Sólo tres \\
carreras de \\
pregrado estaban \\
acreditadas \\
nacionalmente. \\
\end{tabular} & $\begin{array}{l}\text { Existen once carreras acreditadas o } \\
\text { reacreditadas nacionalmente y nueve } \\
\text { en proceso. }\end{array}$ & $\begin{array}{l}\text { Procesos de autoevaluación con } \\
\text { soporte técnico, se han desarrollado } \\
\text { o se encuentran en desarrollo en la } \\
\text { mayor parte de los programas de } \\
\text { pregrado. }\end{array}$ \\
\hline $\begin{array}{l}\text { Limitaciones en } \\
\text { la socialización } \\
\text { del proceso de } \\
\text { autoevaluación. }\end{array}$ & $\begin{array}{l}\text { Plan de Socialización del proceso } \\
\text { autoevaluativo, operando en todos } \\
\text { los niveles institucionales incluidas } \\
\text { las sedes. }\end{array}$ & $\begin{array}{l}\text { Se efectuaron jornadas } \\
\text { institucionales, reuniones sectoriales, } \\
\text { cuentas públicas, documentos y } \\
\text { otras actividades de socialización. }\end{array}$ \\
\hline $\begin{array}{l}\left({ }^{*}\right) \text { Los cuerpos } \\
\text { colegiados que } \\
\text { deben cumplir } \\
\text { funciones de } \\
\text { controlar la } \\
\text { calidad de la } \\
\text { gestión directiva } \\
\text { no siempre } \\
\text { cuentan con } \\
\text { los atributos } \\
\text { necesarios. } \\
\end{array}$ & $\begin{array}{l}\text { Los consejos Superior y Universitario } \\
\text { han tomado un activo rol en el } \\
\text { análisis del Plan de Contingencia } \\
\text { para la acreditación institucional } \\
\text { y de carreras. También en la } \\
\text { reformulación del Plan Estratégico } \\
\text { y en el proceso de autoevaluación } \\
\text { institucional. }\end{array}$ & $\begin{array}{l}\text { Se ha programado la participación de } \\
\text { los cuerpos colegiados. } \\
\text { Los cuerpos colegiados han } \\
\text { modificado en su composición, } \\
\text { producto de procesos eleccionarios } \\
\text { de sus miembros. }\end{array}$ \\
\hline $\begin{array}{l}\left(^{*}\right) \text { El proceso de } \\
\text { autoevaluación } \\
\text { no consideró en } \\
\text { profundidad, } \\
\text { información sobre } \\
\text { sedes. }\end{array}$ & $\begin{array}{l}\text { El nuevo proceso de autoevaluación } \\
\text { consideró, en todas sus fases, } \\
\text { información sobre la gestión y la } \\
\text { docencia que se imparte en las sedes. } \\
\text { Se incluye entre los apéndices del } \\
\text { Informe de Autoevaluación: el Plan } \\
\text { de Contingencia para la acreditación } \\
\text { institucional y de carreras, el cual } \\
\text { contiene un plan de mejoramiento } \\
\text { tanto de campus como sedes. } \\
\text { Se incluye en el Informe de } \\
\text { Autoevaluación un capítulo especial } \\
\text { sobre las sedes }\end{array}$ & $\begin{array}{l}\text { Se consideraron las sedes en las } \\
\text { encuestas estamentales. } \\
\text { La estructura del Informe de } \\
\text { Autoevaluación considera el examen } \\
\text { detallado de todas las sedes. } \\
\text { Se efectuó una consultoría externa } \\
\text { para el diagnóstico de las sedes, } \\
\text { además de un proceso de análisis de } \\
\text { las sedes a través de resultados de } \\
\text { visitas de autoridades superiores. } \\
\text { Elaboración de análisis diagnósticos } \\
\text { y de Planes de Desarrollo por sede. }\end{array}$ \\
\hline
\end{tabular}


158 MODELO DE RESPUESTA A LA ACREDITACIÓN INSTITUCIONAL - Andrea R. Minte, Daniel A. López

\begin{tabular}{|c|c|c|}
\hline $\begin{array}{l}\text { Evaluaciones de } \\
\text { desempeño poco } \\
\text { eficaces. }\end{array}$ & $\begin{array}{l}\text { Se inicia un Sistema de Evaluación } \\
\text { de Desempeño del personal } \\
\text { administrativo (SED). } \\
\text { Formalización de un sistema de } \\
\text { evaluación de desempeño de } \\
\text { personal docente. }\end{array}$ & $\begin{array}{l}\text { A través de una consultoría externa, } \\
\text { se elaboró un sistema de evaluación } \\
\text { de desempeño administrativo. } \\
\text { Se perfeccionó y decretó un nuevo } \\
\text { mecanismo de evaluación de } \\
\text { desempeños docentes, basado en el } \\
\text { logro de compromisos individuales y } \\
\text { en un reglamento de calificación del } \\
\text { desempeño. }\end{array}$ \\
\hline $\begin{array}{l}\text { Deficientes } \\
\text { condiciones de } \\
\text { funcionamiento } \\
\text { en Sedes donde se } \\
\text { imparten a lo largo } \\
\text { del país, programas } \\
\text { tecnológicos y } \\
\text { para trabajadores. } \\
\text { Los principales } \\
\text { problemas son los } \\
\text { siguientes: }\end{array}$ & & \\
\hline $\begin{array}{l}\left({ }^{*}\right) \text { Gran número de } \\
\text { sedes a lo largo del } \\
\text { país, lo que hace } \\
\text { difícil su gestión. }\end{array}$ & $\begin{array}{l}\text { Existieron ingresos en } 2007 \text { a } \\
\text { programas impartidos sólo en } 14 \\
\text { sedes. }\end{array}$ & $\begin{array}{l}\text { Se elaboró e implementó Plan } \\
\text { de Mejoramiento de sedes en } \\
\text { infraestructura y equipamiento. } \\
\text { Se eliminaron los ingresos en sedes, } \\
\text { reduciéndose de las } 38 \text { observadas en } \\
\text { el Informe del Comité de Pares, a } 14 \text {. }\end{array}$ \\
\hline \begin{tabular}{|l|}
$*)$ Programas \\
tecnológicos y \\
de trabajadores \\
en una amplia \\
variedad de áreas \\
disciplinarias.
\end{tabular} & $\begin{array}{l}\text { En } 2007 \text { sólo se ofrecieron en las } \\
\text { sedes, programas docentes en tres } \\
\text { áreas disciplinarias. }\end{array}$ & $\begin{array}{l}\text { Programas sólo tres áreas } \\
\text { disciplinarias: Administración / } \\
\text { Ciencias Sociales / Tecnologías. }\end{array}$ \\
\hline $\begin{array}{l}(*) \text { Cantidad de } \\
\text { programas. }\end{array}$ & $\begin{array}{l}\text { En } 2007 \text { hubo ingresos en } 13 \\
\text { programas profesionales y } 13 \\
\text { técnicos. }\end{array}$ & $\begin{array}{l}\text { No se ha diversificado la oferta de } \\
\text { programas y se están adoptando } \\
\text { medidas para acotar el número de } \\
\text { programas. }\end{array}$ \\
\hline \begin{tabular}{|l|}
$*)$ Cantidad de \\
programas en \\
Educación, los \\
cuales deben ser \\
acreditados en \\
forma obligatoria. \\
\end{tabular} & $\begin{array}{l}\text { Desde } 2005 \text { se suprimieron los } \\
\text { ingresos a la carrera de Educación } \\
\text { General Básica. }\end{array}$ & $\begin{array}{l}\text { A partir de la medida de } \\
\text { disminución de la oferta, en el año } \\
\text { 2009, no existirán alumnos de esta } \\
\text { área en las sedes. }\end{array}$ \\
\hline $\begin{array}{l}\text { (*) Problemas de } \\
\text { infraestructura. }\end{array}$ & $\begin{array}{l}\text { Está en ejecución un plan formal de } \\
\text { inversiones en infraestructura de las } \\
\text { sedes. }\end{array}$ & $\begin{array}{l}\text { Se generó un plan de inversiones, con } \\
\text { asesoría de arquitectos y diseñadores. } \\
\text { Se aprobó un total de } \$ 750 \text { millones } \\
\text { para mejorar la infraestructura y } \\
\text { condiciones materiales de trabajo y } \\
\text { servicios. } \\
\text { Se mejoraron y cambiaron locales de } \\
\text { ocho sedes. }\end{array}$ \\
\hline
\end{tabular}




\begin{tabular}{|c|c|c|}
\hline $\begin{array}{l}\left({ }^{*}\right) \text { Desigual nivel } \\
\text { de desarrollo, } \\
\text { respecto del } \\
\text { existente en sedes, } \\
\text { en los campus } \\
\text { Osorno y Puerto } \\
\text { Montt, el que } \\
\text { se ha producido } \\
\text { a costa de los } \\
\text { déficits existentes } \\
\text { en las sedes. }\end{array}$ & $\begin{array}{l}\text { La reinversión en sedes se ha } \\
\text { incrementado sustantivamente, } \\
\text { existiendo partidas explícitas en el } \\
\text { presupuesto del año } 2007 . \\
\text { Alrededor del 30\% de los activos } \\
\text { fijos se invirtieron en lugares } \\
\text { distintos de Osorno o Puerto Montt. }\end{array}$ & $\begin{array}{l}\text { La definición formal de las sedes en } \\
\text { la estructura territorial, aprobada por } \\
\text { los consejos Superior y Universitario, } \\
\text { establece las funciones de las sedes. } \\
\text { El Instituto de Educación Continua } \\
\text { deberá lograr el cumplimiento de } \\
\text { estándares semejantes a los existentes } \\
\text { en campus en docencia de pregrado. }\end{array}$ \\
\hline $\begin{array}{l}\text { (*) Mecanismos } \\
\text { para garantizar } \\
\text { recursos } \\
\text { humanos físicos } \\
\text { y materiales, } \\
\text { insuficientes. }\end{array}$ & $\begin{array}{l}\text { Está en implementación la } \\
\text { organización interna del Instituto } \\
\text { de Educación Continua, del cual } \\
\text { dependen temporalmente todas las } \\
\text { sedes. }\end{array}$ & $\begin{array}{l}\text { Aprobación del Instituto de } \\
\text { Educación Continua y de su } \\
\text { organización interna. El principal } \\
\text { objetivo es garantizar recursos } \\
\text { financieros y físicos suficientes } \\
\text { para cumplir adecuadamente sus } \\
\text { funciones. }\end{array}$ \\
\hline $\begin{array}{l}(*) \text { Falta } \\
\text { de ayudas } \\
\text { estudiantiles. }\end{array}$ & $\begin{array}{l}\text { Sólo en } 2006 \text { se dispuso de } \$ 128 \\
\text { millones en aportes propios y de } \$ 91 \\
\text { millones de aportes externos, para } \\
\text { financiamiento de los estudios de } \\
\text { alumnos de las sedes. } \\
\text { Esta información no fue incluida } \\
\text { en informe anterior porque se } \\
\text { consideraron sólo los beneficios a } \\
\text { que acceden alumnos con ingresos } \\
\text { PSU. }\end{array}$ & $\begin{array}{l}\text { Se implementará una Unidad de } \\
\text { Apoyo Social en el Instituto de } \\
\text { Educación Continua. }\end{array}$ \\
\hline $\begin{array}{l}(*) \text { Falta de } \\
\text { perfeccionamiento } \\
\text { docente. }\end{array}$ & $\begin{array}{l}\text { En mayo del } 2007 \text { se inició } \\
\text { un Diplomado en Docencia } \\
\text { Universitaria de dos módulos, uno } \\
\text { por semestre en todas las sedes. } \\
\text { El } 2006 \text { se efectuaron talleres en: } \\
\text { "Diseño de planes de estudio" } \\
\text { y "Fortalecimiento de prácticas } \\
\text { pedagógicas". }\end{array}$ & $\begin{array}{l}\text { Se aprobó un Plan de Capacitación } \\
\text { Docente, en el que han participado } \\
\text { alrededor de } 1.000 \text { profesores. }\end{array}$ \\
\hline $\begin{array}{l}* \text { No } \\
\text { seguimiento } \\
\text { de alumnos y } \\
\text { egresados. }\end{array}$ & $\begin{array}{l}\text { Se cuenta con indicadores de } \\
\text { eficiencia pedagógica. }\end{array}$ & $\begin{array}{l}\text { El Instituto de Educación Continua } \\
\text { posee una unidad de registro y } \\
\text { seguimiento. } \\
\text { Se elabora el proyecto de creación } \\
\text { del Centro de Ex Alumnos. }\end{array}$ \\
\hline
\end{tabular}




\begin{tabular}{|c|c|c|}
\hline $\begin{array}{l}\left(^{*}\right) \text { Falta de } \\
\text { sistema de } \\
\text { controles de } \\
\text { calidad. }\end{array}$ & $\begin{array}{l}\text { 100\% de los programas de } \\
\text { asignaturas responde a un formato } \\
\text { nacional (disponibles en plataforma } \\
\text { virtual). } \\
\text { Actualización de contenidos en todas } \\
\text { las asignaturas. } \\
\text { Implementación de análisis } \\
\text { estratégico y plan de mejoramiento, } \\
\text { por sede y por carrera. } \\
\text { Pruebas nacionales. } \\
\text { Jerarquización de académicos. } \\
\text { Programa PROCALIDAD, que evalúa } \\
\text { y acredita internamente programas } \\
\text { de pregrado sin ingresos a través de } \\
\text { la PSU, dependiente de la Dirección } \\
\text { de Aseguramiento de Calidad y } \\
\text { que opera actualmente con dos } \\
\text { programas nacionales. }\end{array}$ & $\begin{array}{l}\text { Plan de control de calidad en sedes, } \\
\text { dirigido por la Vicerrectoría de } \\
\text { Gestión Corporativa. } \\
\\
\text { Creación e implementación de } \\
\text { Programa PROCALIDAD. }\end{array}$ \\
\hline $\begin{array}{l}{ }^{*} \text { ) Deficitaria } \\
\text { provisión } \\
\text { de recursos } \\
\text { educacionales. }\end{array}$ & $\begin{array}{l}\text { Se ha incrementado la provisión } \\
\text { de computadores y material } \\
\text { bibliográfico. } \\
650 \text { equipos computacionales. } \\
\text { Elaboración de } 29 \text { textos de } \\
\text { autoaprendizaje. }\end{array}$ & $\begin{array}{l}\text { Se consideró la inversión en libros } \\
\text { y computadores en el presupuesto } \\
\text { institucional del } 2007 . \\
\text { Convenios con editoriales Lom y } \\
\text { Pearson para edición de textos de } \\
\text { autoaprendizaje. }\end{array}$ \\
\hline $\begin{array}{l}(*) \text { Sistemas } \\
\text { bibliotecarios } \\
\text { insuficientes. }\end{array}$ & $\begin{array}{l}\text { Se ha mejorado la dotación de } \\
\text { bibliografía básica y se elabora } \\
\text { proyecto de Biblioteca Virtual. } \\
\text { Compra de } 19.500 \text { libros. }\end{array}$ & $\begin{array}{l}\text { Se dispuso en el presupuesto } \\
\text { institucional del } 2007 \text { de } \$ 170 \\
\text { millones de pesos. }\end{array}$ \\
\hline $\begin{array}{l}\text { (*) No } \\
\text { consideración de } \\
\text { sedes en proceso } \\
\text { de autoevaluación, } \\
\text { particularmente } \\
\text { de informantes } \\
\text { claves. } \\
\end{array}$ & \begin{tabular}{|l|} 
El Informe de autoevaluación \\
considera a las sedes, en todos los \\
procesos y mecanismos, iguales a los \\
utilizados en los campus.
\end{tabular} & $\begin{array}{l}\text { Se han efectuado procesos de } \\
\text { socialización; participación en } \\
\text { encuestas y entrevistas; cada sede } \\
\text { elaboró un análisis estratégico y su } \\
\text { plan de mejoramiento. }\end{array}$ \\
\hline $\begin{array}{l}(*) \text { Debilidad } \\
\text { en el análisis } \\
\text { estratégico. }\end{array}$ & $\begin{array}{l}\text { Cada sede efectuó un análisis } \\
\text { estratégico y fue integrado para el } \\
\text { conjunto de ellas respaldada con } \\
\text { información estadística. }\end{array}$ & $\begin{array}{l}\text { Definición de un modelo de análisis } \\
\text { estratégico. } \\
\text { Consultoría efectuada por la } \\
\text { consultora Akademika. }\end{array}$ \\
\hline $\begin{array}{l}(*) \text { Falta de } \\
\text { requisitos } \\
\text { mínimos de } \\
\text { funcionamiento } \\
\text { para una sede. }\end{array}$ & $\begin{array}{l}\text { Existen requisitos mínimos en: } \\
\text { infraestructura, equipamiento y } \\
\text { recursos humanos. }\end{array}$ & $\begin{array}{l}\text { Se definieron estándares de } \\
\text { infraestructura y equipamiento. } \\
\text { Se definió tipo de contrato y perfil } \\
\text { académico de directivos. } \\
\text { Se establece estándares para } \\
\text { académicos. }\end{array}$ \\
\hline
\end{tabular}




\begin{tabular}{|c|c|c|}
\hline $\begin{array}{l}(*) \text { No solución } \\
\text { de carencias de } \\
\text { entrada de los } \\
\text { alumnos. }\end{array}$ & $\begin{array}{l}\text { Aplicación de pruebas diagnósticas } \\
\text { y diseño de talleres remediales en } \\
\text { comprensión lectora y matemáticas a } \\
\text { partir del } 2008 \text {. }\end{array}$ & $\begin{array}{l}\text { Proyecto de talleres remediales (en } \\
\text { elaboración). }\end{array}$ \\
\hline $\begin{array}{l}\text { (*) Vacantes } \\
\text { basadas sólo } \\
\text { en la demanda } \\
\text { y requisitos } \\
\text { de ingresos } \\
\text { insuficientes. }\end{array}$ & $\begin{array}{l}\text { Exigencias para ingreso a programas. } \\
\text { Vacantes de acuerdo a disponibilidad } \\
\text { física adecuada. }\end{array}$ & $\begin{array}{l}\text { Plan de control de calidad } \\
\text { dependiente de la Vicerrectoría de } \\
\text { Gestión Corporativa. }\end{array}$ \\
\hline $\begin{array}{l}(*) \text { Sistema } \\
\text { de contratos y } \\
\text { remuneraciones } \\
\text { no favorecen la } \\
\text { calidad. }\end{array}$ & $\begin{array}{l}\text { Los directivos y coordinadores tienen } \\
\text { nuevos vínculos contractuales con la } \\
\text { universidad, asociados a funciones } \\
\text { directivas y administrativas } \\
\text { claramente definidas. }\end{array}$ & $\begin{array}{l}\text { Se modificaron los contratos } \\
\text { de directivos de sedes y de los } \\
\text { programas. }\end{array}$ \\
\hline $\begin{array}{l}\text { (*) Falta de } \\
\text { mecanismos de } \\
\text { evaluación de } \\
\text { personal y de } \\
\text { un sistema de } \\
\text { jerarquización. }\end{array}$ & $\begin{array}{l}\text { Se aplicará un instrumento estándar } \\
\text { de evaluación docente. } \\
\text { Los profesores serán jerarquizados } \\
\text { según normas institucionales. }\end{array}$ & $\begin{array}{l}\text { Se elabora instrumento estándar } \\
\text { nacional de evaluación docente. }\end{array}$ \\
\hline $\begin{array}{l}(*) \text { Planes y } \\
\text { programas no } \\
\text { equivalentes a } \\
\text { los existentes en } \\
\text { Osorno y Puerto } \\
\text { Montt. }\end{array}$ & $\begin{array}{l}\text { Los programas se uniformaron en el } \\
\text { nivel nacional y se está en proceso de } \\
\text { actualización. }\end{array}$ & $\begin{array}{l}\text { Aplicación de un Plan de Control } \\
\text { de Calidad por la Vicerrectoría de } \\
\text { Gestión Corporativa. }\end{array}$ \\
\hline $\begin{array}{l}(*) \text { Débil control } \\
\text { de gestión. }\end{array}$ & $\begin{array}{l}\text { Las sedes han sido incorporadas } \\
\text { en la gestión administrativa en el } \\
\text { sistema eDelfos. La gestión docente } \\
\text { lo será a partir del } 2009 \text { al igual que } \\
\text { el conjunto de la universidad. }\end{array}$ & $\begin{array}{l}\text { Adquisición y funcionamiento del } \\
\text { sistema integrado de gestión eDelfos }\end{array}$ \\
\hline $\begin{array}{l}*) \\
\text { Desconocimiento } \\
\text { de políticas, } \\
\text { objetivos y } \\
\text { programas por } \\
\text { directivos y } \\
\text { académicos de } \\
\text { sedes. }\end{array}$ & $\begin{array}{l}\text { Se han sostenido reuniones con } \\
\text { directivos, académicos y se han } \\
\text { difundido el Plan de Contingencia } \\
\text { para la acreditación institucional y } \\
\text { de carreras. }\end{array}$ & $\begin{array}{l}\text { Aplicación del Plan de Socialización } \\
\text { en todos los niveles de la } \\
\text { universidad. }\end{array}$ \\
\hline
\end{tabular}


162 MODELO DE RESPUESTA A LA ACREDITACIÓN INSTITUCIONAL - Andrea R. Minte, Daniel A. López

\begin{tabular}{|l|l|l|}
\hline $\begin{array}{l}\left.*^{*}\right) \text { Deficientes } \\
\text { sistemas de } \\
\text { comunicación con } \\
\text { campus. }\end{array}$ & $\begin{array}{l}\text { 50\% de carreras con uso de } \\
\text { plataformas. Sistema de conexión } \\
\text { remota. }\end{array}$ & $\begin{array}{l}\text { Licitación nacional de los servicios } \\
\text { de conexión remota (Telmex). }\end{array}$ \\
\hline $\begin{array}{l}\text { (*) Informe de } \\
\text { autoevaluación } \\
\text { incompleto }\end{array}$ & $\begin{array}{l}\text { El informe contiene información } \\
\text { actualizada y una definición clara } \\
\text { para campus y sedes. }\end{array}$ & $\begin{array}{l}\text { Se recopiló y analizó } \\
\text { exhaustivamente información sobre } \\
\text { todos los componentes internos. } \\
\text { Al año 2006 la universidad en su } \\
\text { estructura interna hacía la distinción } \\
\text { entre campus y nodos; a contar del } \\
\text { año en referencia ha cambiado esta } \\
\text { última nomenclatura a "sede", para } \\
\text { asimilar los criterios de la CNAP. }\end{array}$ \\
\hline
\end{tabular}

$\left({ }^{*}\right)$ Aspectos señalados en el dictamen de no acreditación de la CNAP y/o en el informe del comité de pares en el primer proceso de acreditación institucional.

En forma paralela, especialmente en la última fase, se realizó un proceso planeado de socialización a cargo de las vicerrectorías Académica y de Gestión Corporativa. Todos los estamentos de la universidad fueron involucrados en este proceso. Los dirigentes estudiantiles asumieron una importante función en la socialización hacia sus pares y se evidenció un gran interés en toda la comunidad universitaria por conocer y participar de los diversos encuentros, reuniones de trabajo y actividades organizadas en torno al proceso de acreditación institucional. Como evidencia del entusiasmo de los estudiantes, las encuestas de satisfacción que se realizaron sólo a través de la página web institucional superaron las 2.800 respuestas.

\section{Consideraciones finales}

El modelo de respuesta a la acreditación institucional de la Universidad de Los Lagos considera un sistema de evaluación ex dure, de control y retroalimentación. Ello debe asociarse con la instalación formal de procesos de planificación y control estratégico en el ámbito directivo, los cuales eventualmente deberían extenderse a los departamentos académicos, unidades de base del funcionamiento institucional, puesto que de ellos dependen las carreras y se adscriben los académicos.

Asumir la no acreditación institucional como una oportunidad significó en la práctica poner en acción cambios de distinta magnitud 
y cobertura que permitieron superar debilidades manifiestas. De este modo la autoevaluación sobrepasó el tradicional proceso de autoestudio de la situación institucional, adquiriendo un carácter político. Sólo desde esta perspectiva era posible revertir, en plazos cortos, las deficiencias observadas durante la acreditación institucional.

Las definiciones estratégicas involucraron decisiones integradas y vinculantes. De este modo, la formulación de un modelo de respuesta diseñado por el equipo directivo superior fue un factor clave para enfrentar la autoevaluación institucional en forma sistémica. Asimismo, este modelo permitió considerar que la autoevaluación no es sólo la elaboración de un informe que contiene análisis de datos institucionales y percepciones, sino que también debe incluir estrategias de desarrollo congruentes con los cambios y sistemas de información y socialización de dicha información y de los acuerdos que se logren durante el proceso de autoestudio.

La adopción del modelo de respuesta a la acreditación institucional significó adoptar decisiones complejas. Otras alternativas eran retrasar o no enfrentar los procesos de cambio, refugiándose en resquicios legales. Los cambios generan resistencias, lo que podría traer como consecuencia problemas de gobernabilidad. Adicionalmente, el mejoramiento de la calidad tiene efectos económicos, por cuanto significa incrementar el gasto, lo que en el caso descrito significaba reducir significativamente los ingresos autogenerados. Por lo tanto, el modelo asume también estos riesgos, asociados más a factores políticos que a su implementación.

En el contexto de esta experiencia, la ULagos ha intentado desarrollar una nueva cultura organizacional orientada al logro de la calidad en todo el quehacer académico. Esta nueva cultura organizacional trasciende al hecho puntual de la autoevaluación y puede proyectarse sólo si existe una comprensión madura de las causas y efectos de los procesos de acreditación institucional. Objetivamente, se han logrado avances en materia de mejoramiento y aseguramiento de la calidad. Otra cosa es lograr su perdurabilidad. 
164 MODELO DE RESPUESTA A LA ACREDITACIÓN INSTITUCIONAL - Andrea R. Minte, Daniel A. López

Los procesos de acreditación responden a la irrupción de la cultura corporativa en la educación superior en todo el mundo desde hace más de una década (McNay, 1996). En Chile existe una importante experiencia (OECD/Banco Mundial, 2009; Rodríguez, 2009), aunque no se han desarrollado aún procesos metaevaluativos. Producto de la progresiva mayor proporción del gasto privado en la educación superior, el papel del Estado se ha desplazado desde el financiamiento hasta el control de las instituciones, enfatizando la necesidad de asegurar la calidad de los servicios educativos. Para ello, la acreditación institucional y de carreras se han constituido en los procesos regulatorios de mayor importancia (CINDA, 2007), limitados sólo por las autonomías institucionales. Paralelamente, la existencia de relaciones de mercado determina, incluso en las entidades públicas, la necesidad de autofinanciamiento sobre la base de servicios rentables. Ello genera una tensión entre la necesidad de alcanzar estándares de calidad y lograr la sustentabilidad económica. El caso descrito evidencia el potencial de cambio de los procesos regulatorios, pero también sus tensiones. Su impacto depende obviamente de las determinaciones y desempeños en el ámbito de las entidades de educación superior, pero también de lo que deba y pueda hacer el Estado.

\section{Referencias bibliográficas}

CINDA. (2007) Acreditación y dirección estratégica para la calidad en las universidades. Santiago de Chile: CINDA, pp. 11-32.

Comisión Nacional de Acreditación (CNAP) (2007) El modelo chileno de Acreditación de la Educación Superior (1997-2007). Santiago de Chile: CNAP, 119 pp.

Garrido, Oscar y López, Daniel (2007) La educación superior chilena: hechuras y transformaciones. En: Garrido, Oscar; Nordenflych, María Eugenia y Baldivieso, Silvia. Diseño curricular por competencias. Innovación en la formación profesional. La experiencia de la Universidad de Los Lagos. Universidad de Los Lagos, pp. 11-39.

Hax, Arnaldo y Majluf Nicolás (1996) Gestión Empresa con una visión estratégica. Ediciones Dolmen.

Himmel, Erica y Maltes, Sergio (1992) Planificación, Gestión y Control Estratégico en la Universidad. En: CINDA. Administración Universitaria 
en América Latina. Una perspectiva estratégica. Santiago de Chile: CINDA, pp.11-130

McNay, Ian (1996) Gestión de la educación superior en diferentes niveles. Santiago de Chile: Seminarios/Consejo Superior de Educación, pp. 14-28.

Olve, Nils-Göran; Roy, Jan y Wetter, Magnus (2000) Implantando y gestionando el Cuadro de Mando Integral. Guía práctica del Balanced Scorecard. España: Gestión.

Rodríguez, Emilio (2009) Rendición de cuenta pública de la Comisión Nacional de Acreditación. Santiago de Chile: Comisión Nacional de Acreditación.

Agradecemos a todos quienes contribuyeron con documentos e informes durante el segundo proceso de autoevaluación institucional. A Susan Angus por su ayuda en la transcripción del texto. A los evaluadores externos que efectuaron sugerencias que mejoraron este artículo.

Recibido: 4 de mayo de 2009

Aceptado: 28 de septiembre de 2009 